http://ejournal.undip.ac.id/index.php/kapal

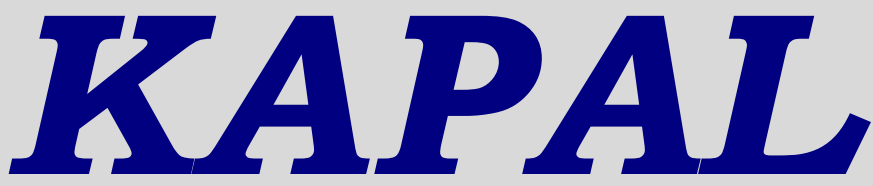

\title{
Judul Studi Perbandingan Performa Kapal Trimaran, Katamaran, dan Monohull Sebagai Kapal Penyeberangan di Kepulauan Karimunjawa
}

\author{
Berlian Arswendo Adietya ${ }^{1)}$, Elvira Dwi Gustiarini ${ }^{1)}$ \\ ${ }^{1)}$ Departemen Teknik Perkapalan, Fakultas Teknik, Universitas Diponegoro \\ Jl. Prof. Soedarto, SH, Kampus Undip Tembalang, Semarang, Indonesia 50275
}

diajukan pada : 11/04/18 direvisi pada $: 24 / 04 / 18 \quad$ diterima pada $: 17 / 05 / 18$

\begin{abstract}
Abstrak
Daerah wisata yang menarik dan terkenal di Pulau jawa salah satunya adalah Kepulauan Karimunjawa. Karimunjawa adalah kepulauan di Laut Jawa yang termasuk dalam Kabupaten Jepara, Jawa Tengah. Fasilitas pendukung pariwisata atau alat transportasi di sekitar Kepulauan Karimunjawa dirasa kurang, padahal banyak sekali pulau-pulau yang memiliki keindahan alamnya. Hal ini menunjukkan bahwa diperlukan usaha untuk mengembangkan teknologi kapal penyebarangan ke pulau-pulau salah satunya ke karimunjawa. Tujuan utama penelitian ini adalah studi perbandingan performa kapal trimaran, katamaran dan monohull sebagai kapal penyebrangan di kepulauan karimunjawa. Metodologi yang dipergunakan dalam penelitian yaitu membandingkan stabilitas dan olah gerak dari kapal trimaran, katamaran dan monohull. Dari hasil analisa didapatkan desain kapal katamaran yang memiliki nilai hambatan paling kecil pada kecepatan 24 knot adalah Catamaran sebesar 177,8 kN dengan power 3463,6 HP dan desain catamaran yang memiliki stabilitas yang baik, dengan simulasi kriteria semuanya memenuhi standar IMO.
\end{abstract}

Copyright @ 2018, KAPAL, 1829-8370 (p), 2301-9069(e)

Kata Kunci : KapalPenyebrangan, Performa Kapal, KepulauanKarimunjawa

\section{PENDAHULAN}

Daerah wisata yang menarik dan terkenal di Pulau jawa salah satunya adalah Kepulauan Karimunjawa. Karimunjawa kini dikembangkan menjadi pesona wisata Taman Laut yang mulai banyak digemari wisatawan lokal maupun mancanegara. Taman Nasional Karimunjawa merupakan gugusan kepulauan berjumlah 22 pulau yang terletak di Laut Jawa, mempunyai luas 111.625 Ha. Taman Nasional Karimunjawa ditetapkan sebagai Cagar Alam Laut melalui SK Menhut No.123/Kpts-II/1986 kemudian pada tahun 1999 melalui Keputusan Menhutbun No.78/Kpts-II/1999 Cagar Alam Karimunjawa dan perairan sekitarnya seluas 111.625 Ha diubah

*) Penulis Korespondensi :

Email : berlianarswendokapal@gmail.com menjadi Taman Nasional dengan nama Taman Nasional Karimunjawa. Tahun 2001 sebagian luas kawasan TN Karimunjawa seluas 110.117,30 Ha ditetapkan sebagai Kawasan Pelestarian Alam Perairan dengan Keputusan Menhut No.74/KptsII/2001.

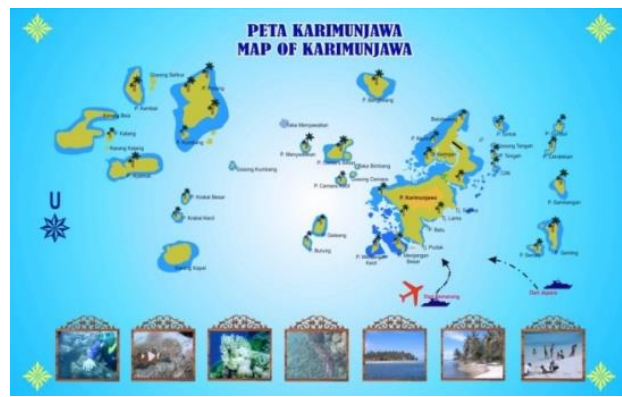

Gambar 1. Peta Karimunjawa (http://rankga.wordpress.com) 
Fasilitas pendukung pariwisata atau alat transportasi di sekitar Kepulauan Karimunjawa dirasa kurang, padahal banyak sekali pulau-pulau yang memiliki keindahan alamnya. Karena kebanyakan para wisatawan hanya fokus di Pulau Karimunjawa sebagai pulau utama dari Kepulauan Karimunjawa. Hal ini sungguh sangat disayangkan karena potensi Pulau lain juga sangat indah. Untuk saat ini akses untuk mengunjungi pulau lain hanya menggunakan perahu kecil yang memiliki mesin diatas dek. Jika cuaca buruk tentu kapal antar pulau ini tidak berani melaut karena sangat beresiko.

Terdapat beberapa penelitian terkait mengenai studi perbandingan performa kapal trimaran, katamaran, dan monohull diantaranya adalah mengenai pengaruh variasi bentuk hull kapal catamaran terhadap besar hambatan total menggunakan CFD yang bertujuan untuk mendapatkan konfigurasi kapal katamaran dengan variasi bentuk dan lebar lambung yang memiliki hambatan paling kecil dengan menggunakan pendekatan Computational Fluid Dynamic (CFD) [1]. Selanjutnya Pengaruh variasi bentuk buritan kapal terhadap hambatan total menggunakan metode CFD [2]. Stabilitas dan seakeeping kapal trimaran Glass Bottom juga dikaji untuk diaplikasikan di Pulau Karimun Jawa. [3]

Selanjutnya penelitian lain mengenai aplikasi penggunaan kapal katamaran untuk kapal SAR di pantai Gunung Kidul Yogyakarta [4]. Adapun analisis mengenai seakeeping dalam hal slamming untuk kapal monohull telah dilakukan oleh [5] dan mengenai bentuk demihull terbaik pada kapal katamaran dalah kualitas seakeeping telah dilakukan oleh [6]. Adapun aplikasi CFD dalam menghitung / mensimulasikan performa hambatan dan seakeeping telah banyak dilakukan diantaranya oleh [7] dengan menggunakan metode Moving Grid. Kemudian oleh [8] penggunaan CFD digunakan untuk penggati metode panel yang sering digunakan dalam analisis seakeeping (termasuk dalam penelitian ini).

Tujuan dari penelitian ini dapat mengetahui nilai hidrostatik, stabilitas dan hambatan pada kapal monohull, katamaran, dan trimaran. Penelitian ini penting bagi perkembangan teknologi kapal penyebrangan, yang mana dengan adanya penelitian ini maka akan didapatkan desain kapal penyebrangan dengan menggunakan trimaran, katamaran dan monohull hullform. Salah satu keunggulan teknologi kapal penyebrangan dibandingkan dengan kapal tradisional.

Upaya pengembangan desain kapal penyebrangan dilakukan melalui eksplorasi terhadap macam-macam desain trimaran, katamaran dan monohull yang mengkaji karakteristik hidrostatik, stabilitas dan gerakan diatas air. Hasil dari penelitian ini diharapkan mampu memberikan solusi alternatif terhadap kebutuhan transportasi wahana wisata laut untuk menikmati indahnya panorama kepulauan karimunjawa.

Harapannya penilitian ini dapat memberikan solusi alternatif kebutuhan transportasi wahana wisata laut untuk melihat indahnya panorama kepulauan karimunjawa dan meningkatkan daya tarik pariwisata Kepulauan Karimunjawa melalui penyediaan wahana transportasi laut yang nyaman dan aman.

\section{METODE}

Metode penelitian menggunakan pendekatan software, sehingga prosedur yang harus dilakukan adalah mempersiapkan data-data teknis untuk kemudian dilakukan pemodelan dan analisa.

\subsection{Materi Penelitian}

Materi penelitian yang dimaksud dalam penelitian ini meliputi data-data yang akan diproses dalam penelitian antara lain :

\section{- Monohull}

Keuntungan dari monohull adalah bahwa kapal bisa memotong melalui gelombang berat dengan mudah. Dengan membelah melalui gelombang bukan dengan berjalan di atas ombak, kapal ini mampu melaju jauh lebih lancar melalui air. Memiliki hull tunggal yang memuat kargo memungkinkan monohull untuk mendistribusikan berat di mana itu akan memberikan keseimbangan paling stabil saat kapal melakukan perjalanan hingga ke tujuan.

\section{- Catamaran}

Mempunyai dua lambung (demihull) yang mana lambung satu dengan lambung lainnya dihubungkan dengan struktur bridging. Struktur bridging ini bisa mengurangi terjadinya deckwetness karena struktur bridging merupakan sebuah keuntungan kapal katamaran karena menambah tinggi lambung timbul (freeboard) tersebut. Selain itu struktur bridging yang kuat dan merentang diatasnya digunakan untuk menahan momen bending (bendingmoment) dan gaya geser (shearforce) yang besar dan bekerja terhadap garis tengah (centerline) kapal. 


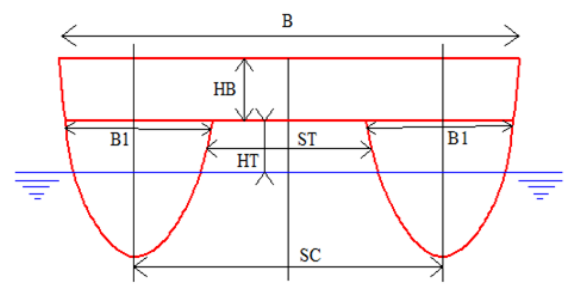

Gambar 2.Penampakan Tengah Kapal Catamaran

- Trimaran.

Bentuk lambung Trimaran pada berbagai kapal tidaklah sama. Terdapat banyak model bentuk badan Trimaran, tetapi secara umum ada dua bentuk dasar dari Trimaran yakni :

1. Trimaran Simestris

2. Trimaran Asimetris

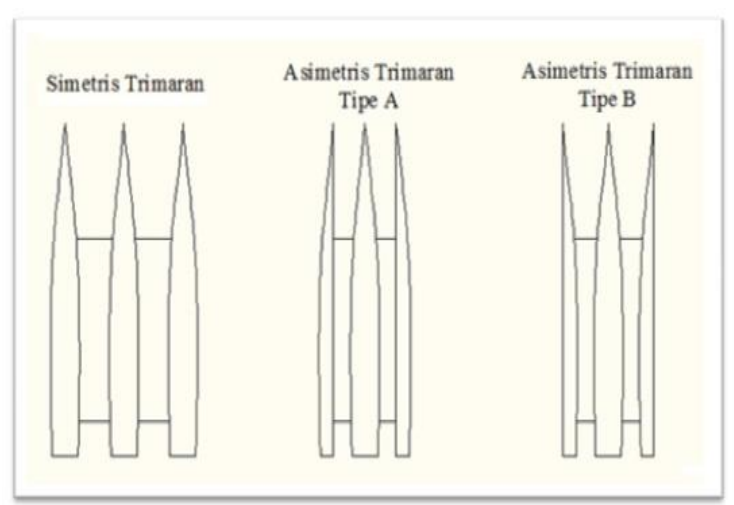

Gambar 3.Jenis Lambung Trimaran

Pemilihan bentuk badan kapal harus didasarkan pada metode yang tepat sehingga hasilnya akan dapat diandalkan. Trimaran dengan geladak yang lebih besar adalah salah satu contoh konsep rancangan yang berhasil dalam mengatasi gerakan oleng yang merupakan kelemahan generic kapal konvensional.

\subsection{Diagram Alir}

$\underline{\text { Yang sudah dilakukan }}$

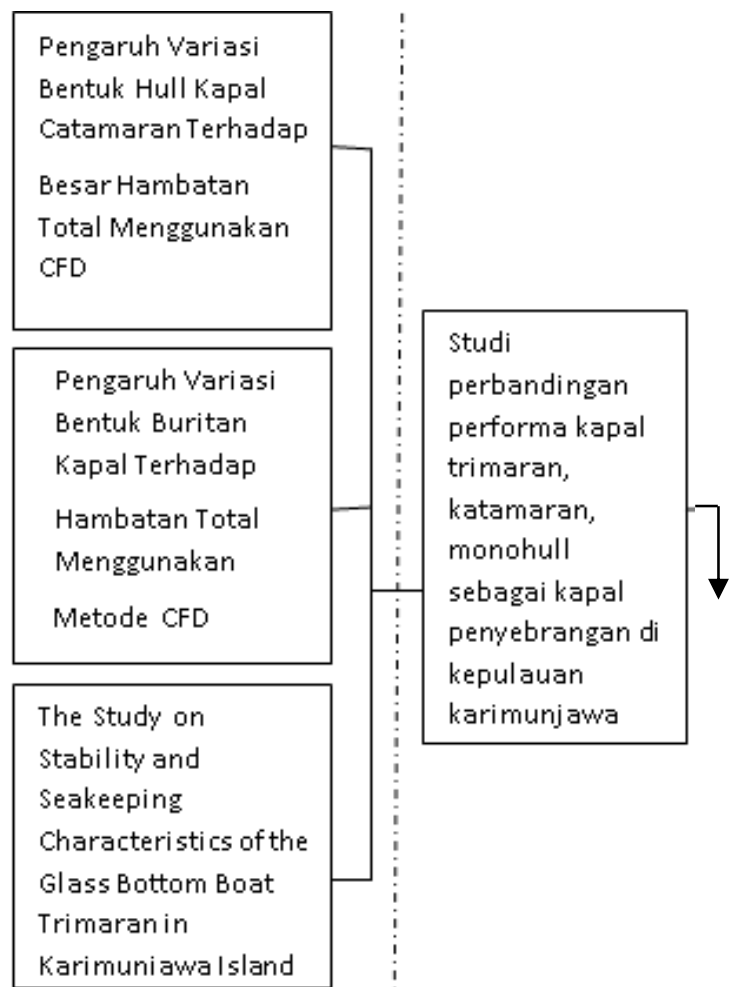

Gambar 4. Diagram Alir (Flowchart) Yang akan dilakukan (Penelitian Dasar FT 2017)

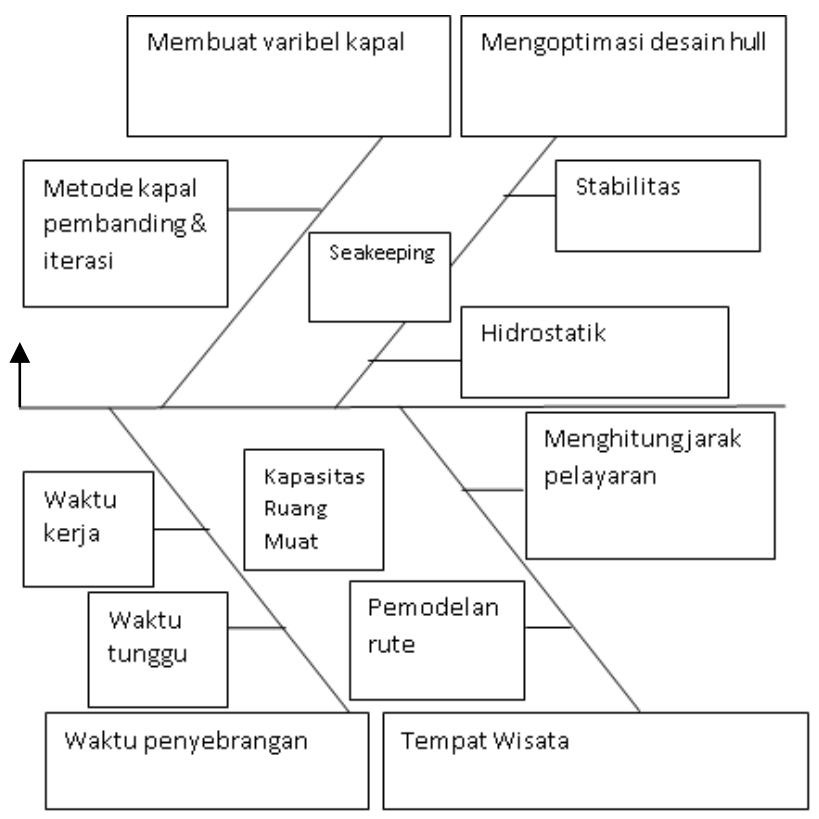

Gambar 5. Diagram Alir (Flowchart) 


\section{HASIL DAN PEMBAHASAN}

\subsection{Requirement}

Untuk menentukan jenis kapal yang akandigunakan untuk wilayah perairan Laut Jawa yangmemiliki gelombang 1 meter, maka akanmembandingkan performa tiga jenis kapal, yaitumonohull, catamaran, dan trimaran dengan memiliki Displacement. Untuk ituperbandingan performanya meliputi hambatan, powerserta stabilitas adalah katamaran simetris streamline,agar gelombang yang dibentuk badan kapal tidakbesar.
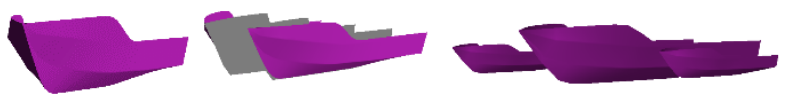

Gambar 5. Model kapal monohull, catamaran, trimaran

Tabel 1. Perbandingan Ukuran Utama

\begin{tabular}{|c|c|c|c|}
\hline Parameter & Monohull & Catamaran & Trimaran \\
\hline Displacement & 206.6 & 206.6 & 206.1 \\
\hline $\begin{array}{l}\text { Volume } \\
\text { (displaced) }\end{array}$ & 201.546 & 201.549 & 201.03 \\
\hline $\begin{array}{l}\text { Draft } \\
\text { Amidships }\end{array}$ & 1.7 & 1.7 & 1.55 \\
\hline $\begin{array}{l}\text { Immersed } \\
\text { depth }\end{array}$ & 1.7 & 1.7 & 1.55 \\
\hline WL Length & 39.101 & 39.28 & 35.462 \\
\hline $\begin{array}{l}\text { Beam max } \\
\text { extents on } \\
\text { WL }\end{array}$ & 6.763 & 10.763 & 21.784 \\
\hline Wetted Area & 260.78 & 442.745 & 331.555 \\
\hline $\begin{array}{l}\text { Max sect. } \\
\text { area }\end{array}$ & 6.825 & 6.825 & 8.621 \\
\hline $\begin{array}{l}\text { Waterpl. } \\
\text { Area }\end{array}$ & 219.693 & 219.695 & 276.898 \\
\hline $\begin{array}{l}\text { Prismatic } \\
\text { coeff. (Cp) }\end{array}$ & 0.755 & 0.752 & 0.658 \\
\hline $\begin{array}{l}\text { Block coeff. } \\
\text { (Cb) }\end{array}$ & 0.448 & 0.446 & 0.168 \\
\hline $\begin{array}{l}\text { Max Sect. } \\
\text { area coeff. } \\
(\mathrm{Cm})\end{array}$ & 0.596 & 0.596 & 0.255 \\
\hline $\begin{array}{l}\text { Waterpl. area } \\
\text { coeff. (Cwp) }\end{array}$ & 0.831 & 0.827 & 0.358 \\
\hline LCB length & 16.854 & 16.855 & 16.793 \\
\hline LCF length & 16.709 & 16.709 & 17.373 \\
\hline LCB $\%$ & 43.105 & 42.908 & 47.354 \\
\hline LCF \% & 42.732 & 42.537 & 48.992 \\
\hline KB & 1.154 & 1.154 & 1.101 \\
\hline $\begin{array}{l}\text { Immersion } \\
\text { (TPc) }\end{array}$ & 2.252 & 2.252 & 2.838 \\
\hline Vs & 24 & 24 & 24 \\
\hline
\end{tabular}

\subsection{Analisis Hambatan}

Dari hasil analisa, diketahui didapatkan desain yang memiliki nilai hambatan paling kecil pada kecepatan 24 knot adalah Catamaran sebesar $177,8 \mathrm{kN}$ dengan power $3463,6 \mathrm{HP}$.

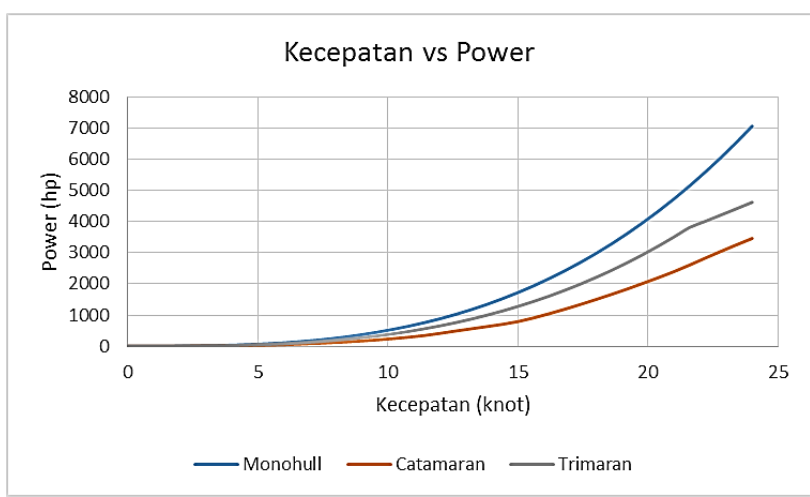

Gambar 6. Perbandingan nilai power

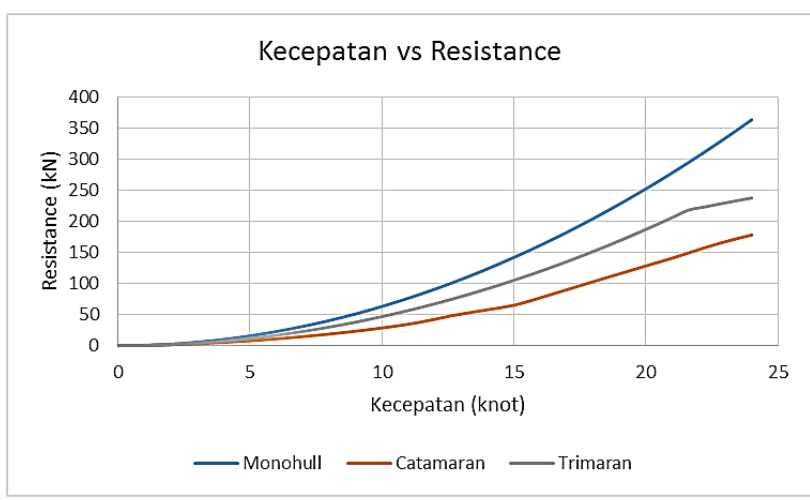

Gambar 7. Perbandingan nilai resistance

\subsection{Analisis Stabilitas}

Jika sebuah kapal memiliki nilai MG kecil, maka nilai periode oleng besar sehingga kapal menjadi lambat untuk ke posisi tegak / ke posisi semula ( momen penegak kecil ). Begitu pula sebaliknya, jika kapal memiliki nilai MG besar, maka nilai periode oleng kecil sehingga kapal menjadi cepat untuk ke posisi tegak / ke posisi semula ( momen penegak besar ).

Tabel 2. Simulasi kondisi

\begin{tabular}{lccc}
\hline Item Name & Kondisi 1 & Kondisi 2 & Kondisi 3 \\
\hline Lightship & 1 & 1 & 1 \\
Mesin Kiri & 1 & 1 & 1 \\
Mesin & 1 & 1 & 1 \\
Tengah & & & \\
Mesin & 1 & 1 & 1 \\
Kanan & 1 & 1 & 1 \\
Sekoci & 0 & 33 & 33 \\
Penumpang & 1 & 1 & 1 \\
Naval Gun & 1 & 1 & 1 \\
Peralatan & 1 & &
\end{tabular}




\begin{tabular}{llll} 
FWT & $85 \%$ & $50 \%$ & $100 \%$ \\
FWT & $85 \%$ & $50 \%$ & $100 \%$ \\
Sewage & $85 \%$ & $50 \%$ & $100 \%$ \\
Tank & $85 \%$ & $50 \%$ & $100 \%$ \\
$\begin{array}{l}\text { Daily Tank } \\
\text { Daily Tank }\end{array}$ & $85 \%$ & $50 \%$ & $100 \%$ \\
$\begin{array}{l}\text { Fuel Oil } \\
\text { Service Tank }\end{array}$ & $85 \%$ & $50 \%$ & $100 \%$ \\
$\begin{array}{l}\text { Fuel Oil } \\
\text { Service Tank }\end{array}$ & $85 \%$ & $50 \%$ & $100 \%$ \\
$\begin{array}{l}\text { Fuel Oil } \\
\text { Tank 1 Kiri }\end{array}$ & $85 \%$ & $50 \%$ & $100 \%$ \\
$\begin{array}{l}\text { Fuel Oil } \\
\text { Tank 1 }\end{array}$ & $85 \%$ & $50 \%$ & $100 \%$ \\
$\begin{array}{l}\text { Fuel Oil } \\
\text { Tank 2 Kiri }\end{array}$ & $85 \%$ & $50 \%$ & $100 \%$ \\
$\begin{array}{l}\text { Fuel Oil } \\
\text { Tank 3 Kiri }\end{array}$ & $85 \%$ & $50 \%$ & $100 \%$ \\
$\begin{array}{l}\text { Fuel Oil } \\
\text { Tank 2 }\end{array}$ & $85 \%$ & $50 \%$ & $100 \%$ \\
$\begin{array}{l}\text { Fuel Oil } \\
\text { Tank 3 } \\
\begin{array}{l}\text { Ceruk } \\
\text { Haluan }\end{array}\end{array}$ & $85 \%$ & $50 \%$ & $100 \%$ \\
\hline
\end{tabular}

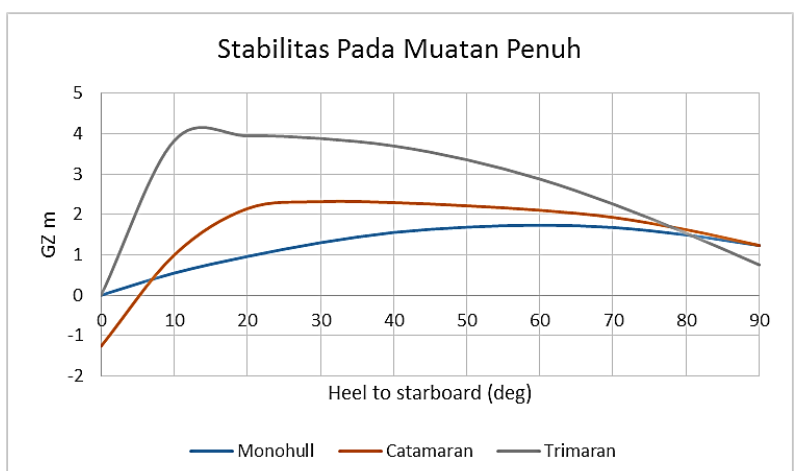

Gambar 8. Hasil Analisa Stabilitas Kondisi 3

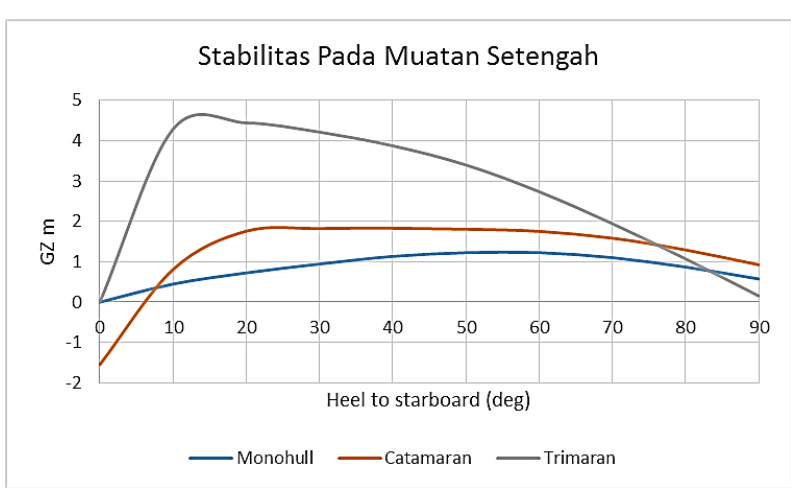

Gambar 9. Hasil Analisa Stabilitas Kondisi 2

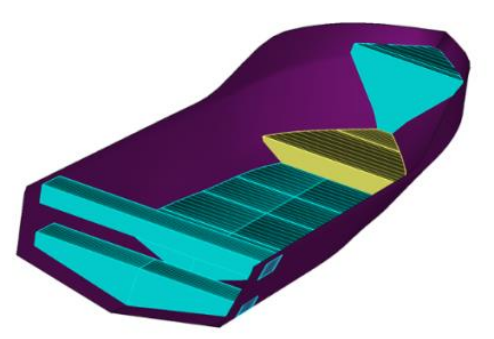

(a)

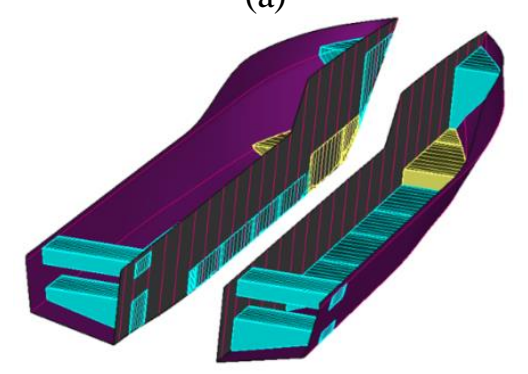

(b)

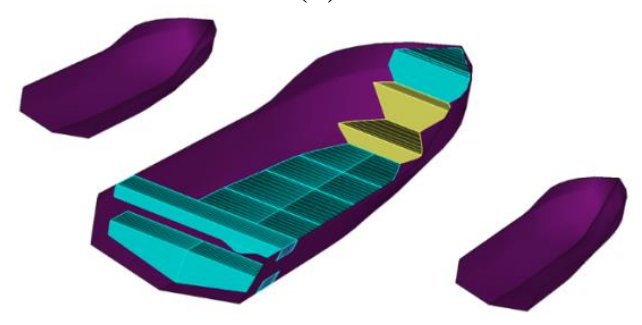

(c)

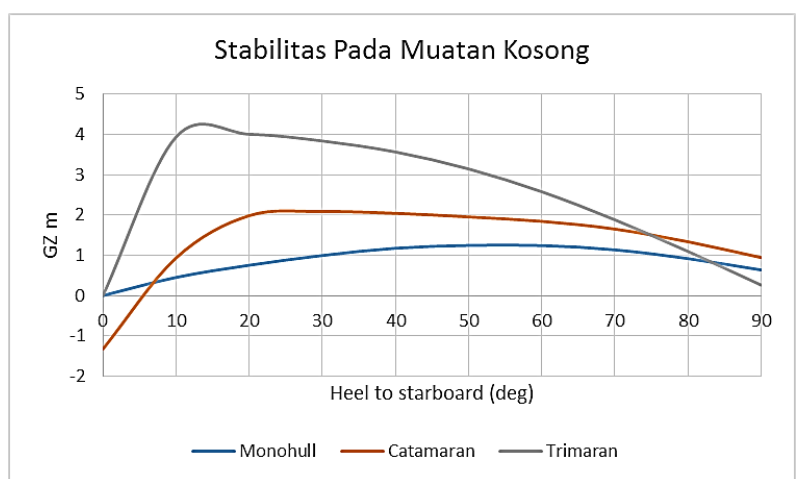

Gambar 10. Hasil Analisa Stabilitas Kondisi 1

Tabel 3. Resume Anlisa Stabilitas Kondisi 1

\begin{tabular}{ccccc}
\hline Crite ria & Value & \multicolumn{3}{c}{ Monohull Catamaran Trimaran } \\
\hline $\begin{array}{c}\text { 3.1.2.1: Area } 0 \text { to } \\
\begin{array}{c}\text { 30 } \\
\text { 3.1.2.1: Area } 0 \text { to }\end{array}\end{array}$ & 5.1566 & Pass & Pass & Pass \\
$\begin{array}{c}\text { 40 } \\
\text { 3.1.2.1: Area } 30\end{array}$ & 1.7189 & Pass & Pass & Pass \\
$\begin{array}{c}\text { to } 40 \\
\text { 3.1.2.2: Max GZ } \\
\text { at 30 or greater }\end{array}$ & 0.2 & Pass & Pass & Pass \\
$\begin{array}{c}\text { 3.1.2.3: Angle of } \\
\text { maximum GZ }\end{array}$ & 25 & Pass & Pass & Fail \\
$\begin{array}{c}\text { 3.1.2.4: Initial } \\
\text { GMt }\end{array}$ & 0.15 & Pass & Pass & Pass \\
\hline
\end{tabular}

Gambar 7. Pendefinisian Loadcase 
Tabel 3. Resume Anlisa Stabilitas Kondisi 2

\begin{tabular}{ccccc}
\hline Crite ria & Value & \multicolumn{3}{c}{ Monohull Catamaran Trimaran } \\
\hline $\begin{array}{c}\text { 3.1.2.1: Area } 0 \text { to } \\
\text { 30 }\end{array}$ & 3.1513 & Pass & Pass & Pass \\
$\begin{array}{c}\text { 3.1.2.1: Area } 0 \text { to } \\
\text { 40 }\end{array}$ & 5.1566 & Pass & Pass & Pass \\
$\begin{array}{c}\text { 3.1.2.1: Area } 30 \\
\text { to } 40\end{array}$ & 1.7189 & Pass & Pass & Pass \\
$\begin{array}{c}\text { 3.1.2.2: Max GZ } \\
\text { at 30 or greater }\end{array}$ & 0.2 & Pass & Pass & Pass \\
$\begin{array}{c}\text { 3.1.2.3: Angle of } \\
\text { maximum GZ }\end{array}$ & 25 & Pass & Pass & Fail \\
$\begin{array}{c}\text { 3.1.2.4: Initial } \\
\text { GMt }\end{array}$ & 0.15 & Pass & Pass & Pass \\
\hline
\end{tabular}

Tabel 3. Resume Anlisa Stabilitas Kondisi 3

\begin{tabular}{ccccc}
\hline Crite ria & Value & Monohull Catamaran Trimaran \\
\hline $\begin{array}{c}\text { 3.1.2.1: Area } 0 \text { to } \\
\text { 30 }\end{array}$ & 3.1513 & Pass & Pass & Pass \\
$\begin{array}{c}\text { 3.1.2.1: Area } 0 \text { to } \\
\text { 40 }\end{array}$ & 5.1566 & Pass & Pass & Pass \\
$\begin{array}{c}\text { 3.1.2.1: Area } 30 \\
\text { to } 40\end{array}$ & 1.7189 & Pass & Pass & Pass \\
$\begin{array}{c}\text { 3.1.2.2: Max GZ } \\
\text { at 30 or greater }\end{array}$ & 0.2 & Pass & Pass & Pass \\
$\begin{array}{c}\text { 3.1.2.3: Angle of } \\
\text { maximum GZ }\end{array}$ & 25 & Pass & Pass & Fail \\
$\begin{array}{c}\text { 3.1.2.4: Initial } \\
\text { GMt }\end{array}$ & 0.15 & Pass & Pass & Pass \\
\hline
\end{tabular}

Berdasarkan hasil analisa stabilitas di atas, dapat disimpulkan desain yang paling optimun dari segi stabilitas adalah kapal Catamaran.

\section{KESIMPULAN}

Berdasarkan hasil analisa diatas, dapat disimpulkan sebagai berikut: 1) Didapatkan desain yang memiliki nilai hambatan paling kecil pada kecepatan 24 knot adalah Catamaran sebesar $177,8 \mathrm{kN}$ dengan power 3463,6 HP. 2) Didapatkan desain catamaran yang memiliki stabilitas yang baik, dengan simulasi kriteria semuanya memenuhi standar IMO.Times

\section{DAFTAR PUSTAKA}

[1] D. Chrismianto, B. A. Adietya dan Y. Sobirin, "PENGARUH VARIASI BENTUK HULL KAPAL CATAMARAN TERHADAP BESAR HAMBATAN TOTAL MENGGUNAKAN CFD," Kapal, vol. 11, no. 2, pp. 99-106, 2014.

[2] D. Chrismianto dan B. A. Adietya, "PENGARUH VARIASI BENTUK BURITAN KAPAL TERHADAP HAMBATAN TOTAL MENGGUNAKAN
METODE CFD," Kapal, vol. 11, no. 3, pp. 154-161, 2014.

[3] B. A. Adietya, A. Widyandari dan A. F. Zakki, "The Study on Stability and Seakeeping Characteristics of the Glass Bottom Boat Trimaran in Karimunjawa Island," IOP Conference Series: Earth and Environmental Science, vol. 135, no. 1, pp. 1-8, 2018.

[4] E. S. Hadi, S. Jokosisworo dan W. Widyanto, "ANALISA PERFORMA HULLFORM PADA PRA PERANCANGAN SPEED BOAT KATAMARAN UNTUK SEARCH AND RESCUE ( SAR ) DI PANTAI GUNUNGKIDUL YOGYAKARTA BERBASIS CFD," Kapal, vol. 9, no. 1, pp. 6 13, 2012.

[5] M. Iqbal dan G. Rindo, "PENGARUH ANTISLAMMING BULBOUS BOW TERHADAP GERAKAN SLAMMING PADA KAPAL PERINTIS 200 DWT," kapal, vol. 13, no. 1, pp. 45-54, 2016.

[6] M. Iqbal dan G. Rindo, "OPTIMASI BENTUK DEMIHULL KAPAL KATAMARAN UNTUK MENINGKATKAN KUALITAS SEAKEEPING," Kapal, vol. 12, no. 1, pp. 19 - 24, 2015.

[7] E. Jahanbakhsh, R. Panahi dan M. S. Seif, "CATAMARAN MOTION SIMULATION BASED ON MOVING GRID TECHNIQUE," Journal of Marine Science and Technology, vol. 17, no. 2, pp. 128 - 136, 2009.

[8] S. P. Kim, "CFD as a seakeeping tool for ship design," International Journal of Naval Architecture and Ocean Engineering, vol. 3, no. 1, pp. 65-71, 2011. 